\title{
Marriage Partner Selection by Heterosexual Couples Living with HIV from Rural Southern Malawi
}

\author{
Belinda Chimphamba Gombachika ${ }^{1,2 *}$, Ellen Chirwa ${ }^{2}$, Johanne Sundby ${ }^{1}$, Address Malata ${ }^{3}$, Alfred Maluwa ${ }^{3}$ and Heidi Fjeld ${ }^{1}$ \\ 1 University of Oslo, Institute of Health and Society, Department of Community Medicine, Oslo, Norway \\ ${ }^{2}$ University of Malawi, Kamuzu College of Nursing, Faculty of Nursing, Blantyre Campus, Blantyre, Malawi \\ ${ }^{3}$ University of Malawi, Kamuzu College of Nursing, Faculty of Nursing, Lilongwe Campus, Lilongwe, Malaw
}

\begin{abstract}
This paper explores marriage partner selection in couples living with HIV using a qualitative research method. The study was conducted in Chikwawa and Chiradzulu districts in Southern Malawi which follow patrilineal and matrilineal marriage traditions, respectively. Data was collected from 20 informants using in-depth interviews from July- December 2010. Four out of 10 matrilineal couples and six out of 10 patrilineal couples established their new marriages when they were HIV-positive. They chose a marriage partner living with HIV because they felt that they would understand each other well and that it was easy to follow the guidelines for HIV positive living thereby negotiating the threat of social stigma from the communities. The results show that, HIV status is important in the decisions that the couples living with HIV make in terms of selecting marriage partners. However, once the new marriage relationships are established based on same HIV positive status, the HIV positive status no longer deters them from having unprotected sexual relationships as evidenced from the children that some of the couples were bearing. The couples indulged in unprotected sex despite being aware that unprotected sex increases the risks of mother to child transmission of HIV and also increases HIV viral load in their bodies. This paper contributes to the literature on living with HIV by focusing on marriage partner selection. Specifically, the findings increase our understanding of how in the pursuit of a normal life people living with HIV decisions to get married, and in the course select the marriage partners that are also living with HIV. We argue that the issue of same status marriage should be dealt with in health programmes in order to limit the risk of new forms of infection. Health care workers and peergroup leaders must be trained on the dangers of HIV super-infection and reproductive decisions, rights, ethics for couples living with HIV. Further studies are needed in Malawi to better inform policy in the formulation of evidence based prevention strategies for couples living with HIV which, in the long run, would address issues of maternal and child mortality from HIV and AIDS.
\end{abstract}

Keywords: Couples; HIV and AIDS; Kinship; Malawi; Marriage; Partner

\section{Introduction}

In the early years of the HIV epidemic, little attention was given to the reproductive decisions among people living with HIV (PLWH) because of the risk of mortality and a few options to reduce mother to child transmission [1]. In recent years, HIV-related morbidity, mortality, and mother to child transmission of HIV during pregnancy, delivery and in the newborn are declining because of antiretroviral therapy (ART/ARV) [2]. HIV infection may now be considered a chronic illness [3] because the ARVs suppress HIV replication which results to increased $\mathrm{CD} 4$ cell count, delayed clinical progression of AIDS and prolonged survival [4]. Consequently there has been a shift in research; whereby efforts are now integrating reproductive decision and HIV and AIDS issues in intervention studies [1,5,6]. With wider reproductive options available to $\mathrm{PLWH}$, evidence emerging from research in developing countries indicates that ART may encourage PLWH receiving treatment to reconsider their reproductive decisions including getting married and having children. These decisions are related to perceptions that ARV allows them to live longer and, enjoy 'normal' social sexual lives, and possibly have healthy, HIV-negative children [2,7-9]. While there are dramatic improvements in some of the key challenges, such as bearing HIV negative children, new challenges have emerged, which include indulgence in risky sexual behavior by couples living with HIV. The risky behaviour for couples living with HIV (CLWH) may be influenced by the type of partners involved [1013].

Some studies have shown that the epidemic is exerting a downward pressure on probabilities of re-marriages following either widowhood or divorce. The fear of HIV-infection is also creating fear of re-marriage as such some people are refusing to marry for fear of finding 'death in marriage'. In such cases, issues of stigmatization due to the AIDS or from suspicions of infidelity, since the primary means of HIV transmission is heterosexual intercourse, have been reported [14, 15]. Oleke et al. [16], further assert that widow re-marriage has decreased due to suspicion that their former husbands might have died from AIDS.

\section{Social context}

Malawi has a total population of $13,077,160$ and HIV is an important challenge to the public health. At 10.6\%, Malawi has one of the highest national HIV prevalence rate in the world. Heterosexual contact is the principal mode of transmission, while mother-to-child transmission accounts for $25 \%$ of all new HIV infections. People of the reproductive age group, 15-49 years, are one of the fastest growing groups being diagnosed with HIV and AIDS (National Statistical Office

*Corresponding author: Belinda Thandizo Chimphamba Gombachika, Institute of Health and Society, Department of Community Medicine, PO Box 1130, Blindern 0318 Oslo, Oslo, Norway, Tel: (+47) 457743 70; Fax: (+47) 228505 90; E-mail: belinda.chimphamba@medisin.uio.no

Received April 03, 2012; Accepted July 19, 2012; Published July 24, 2012

Citation: Gombachika BC, Chirwa E, Sundby J, Malata A, Maluwa A, et al. (2012) Marriage Partner Selection by Heterosexual Couples Living with HIV from Rural Southern Malawi. J AIDS Clinic Res S1:016. doi:10.4172/2155-6113.S1-016

Copyright: (c) 2012 Gombachika BC, et al. This is an open-access article distributed under the terms of the Creative Commons Attribution License, which permits unrestricted use, distribution, and reproduction in any medium, provided the original author and source are credited. 
[NSO], [17]). Malawi is a multi-ethnic country and the ethnic groups can be placed in two broad categories; patrilineal and matrilineal social systems. The northern region is predominantly patrilineal while the central and southern regions are predominantly matrilineal. In this study, ethnicity was not made an explicit point for comparison but marriage organizations.

The societies are totally a married society with the unmarried adults being ridiculed as either barren or prostitutes. On the other hand, religious beliefs that are strongly manifest in these communities stress the importance of marriage [15]. Marriage is marked by the union of the marriage partners as well as their families or lineages where the partners originate. As such, involvement of parents and extended kin is both central and essential to the process of marriage. Where kinship groups are formed by patrilineal descent - father and sons, the residence after marriage is virilocal (patrilocal) i.e. women leave their natal household to live in their husbands' household. A marriage is legitimized by transfer of, a bride price, traditionally cattle or money, locally known as lobola, to the bride's family. Lobola symbolically, transfers a woman's reproductive capacities from her own lineage to that of her husband's agnatic lineage. Property is inherited through agnatic descent and generally men are the decision makers in the domain [18-20]. By contrast, where kinship groups are formed by matrilineal descent, marriage is followed by uxorilocal (matrilocal) residence.

Customary marriages are the common types of marriages in the rural areas of Malawi. The marriage unions involve a whole network of extended family members. This comes along with a wide crosscultural variation in the social cultural rules governing the selection of a partner for marriage. In both social organisations, once a suitable partner is identified, parents look for a mediator who knows both sides to carry out investigations to make sure that the chosen partners come from respectable families. Sometimes the parents help in identifying and selecting suitable partners for their children and once a marriage partner is identified, the children never object to the choices made. Other marriage formalities like lobola or traditional engagement follow. Important key actors in these marriage formalities are the marriage counsellors known as ankhoswe. The counsellors are usually the couple's uncles, who are involved in contracting the marriage. In both patrilineal and matrilineal societies, a marriage is not considered valid unless the ankhoswe have been involved in the officiating of the marriage. Ankhoswe also play a crucial role as mediators between the marriage partners in the case of marriage disputes [14,21,22].

However, marriage practices have changed a lot in Malawi. The factors that have contributed to the change and eradication of these practices are not only HIV and AIDS. Social changes such as economic problems which have resulted in a high cost of living, high unemployment rates, intermarriages, education and modern religion have also affected choice of a marriage partner. The HIV and AIDS epidemic has generated fear, anxiety, and prejudice against PLWH. There is widespread stigma and discrimination against PLWH; being discredited as irresponsible, promiscuous and deserving misfortune. These societal attitudes adversely affect both people's willingness to HIV testing, disclosure of a positive HIV-status, access to ARV's [17] and marriages [22-24].

Several studies in developing countries [25-27] have examined marriage partner selection, serosorting, in men who have sex with men (MSM). These studies do not only have a contextual limitation but focused on MSM. There is paucity of literature regarding selection of marriage partners and serosorting by PLWH in heterosexual relationships. The purpose of the study was to explore marriage partner selection among CLWH in matrilineal and patrilineal communities which was part of a main study on reproductive decisions of couples living with HIV in Malawi. This paper focuses on couples that had re-married partners who were living with HIV. The identified gaps in knowledge will inform the development of policy and intervention programmes to support healthier reproductive options for CLWH in Malawi and in the long run address the maternal mortality due to AIDS in Malawi.

\section{Methodology}

A qualitative approach was deemed optimal because this area has little existing research based knowledge. In addition the area has sensitive, emotive and personal topics that can be captured fully through careful probing using qualitative in-depth interview (IDI). The research questions required the capture of great depth responses regarding PLWH marriage partner selection and also the meaning attached to such experiences in rural matrilineal and patrilineal context.

\section{Study setting}

The informants were recruited from ART Clinics involved in the treatment and care of PLWH at two HIV/AIDS centres in southern Malawi. The centers were Ngabu Health Center, which is situated in Chikhwawa and Ndunde Health Center, which is situated in Chiradzulu. These centers were chosen because they received patients from more remote villages, away from trading centres and main roads that attract people from other districts which was the aim of a bigger study exploring reproductive decisions made by $\mathrm{CLWH}$ in rural matrilineal and patrilineal communities. The two centres offer inpatient and outpatient HIV and AIDS treatment using multidisciplinary teams, and serve primarily low-income individuals from diverse backgrounds. The informants came from catchment areas surrounding these health facilities and the average time to and from the health centers ranged from 1 hour to 3 hours on foot. Both districts face challenges ranging from food insecurity, low accessibility to safe water, low household income levels and poor communication infrastructure coupled with high prevalence of HIV and AIDS [17].

\section{Data collection}

Informants were recruited upon receipt of permission to conduct the study following ethical approval from Internal Ethical Review Boards in Malawi and Norway. Twenty CLWH were recruited in the study using purposive sampling in order to intentionally select 'information-rich cases' [28] that would provide an in-depth understanding of the reproductive decisions of CLWH. In order to achieve maximum variation, the inclusion criteria were; married, HIV-positive (concordant couples), re-married, had informed of each other's HIV status as a couple, living in keeping with the traditions of their communities, were from catchment areas that was served by the two health facilities, Ndunde health centre and Ngabu rural hospital, and in the reproductive age group of 18-49 years [17]. A sample size of 20 informants was determined based on Kuzel [29] and Green and Thorogood [30]. Initially sample size was set at 30 . However, in the design we were aware that the actual sample size could be reduced or increased depending upon data saturation. In this study data saturation was reached with 20 couples (40).

Informants were recruited upon receipt of permission to conduct the study following ethical approval from Internal Ethical Review Boards in Malawi and Norway. Data was collected from JulyDecember 2010 and three months was spent in each study setting. This 
immersion and fluency in vernacular language, (Chichewa), enabled the researcher to internalize, rather than superficially observe patterns of beliefs, fears, expectations, dominant ideas, values and behaviours of the informants [31]. Practical access to the ART clinics was gained through collaboration with the ART clinic co-ordinators. In both sites, the ART clinic co-ordinators identified a contact person with whom the present study was discussed thoroughly. Considerable time was spent with the contact person to ensure that thorough comprehension was gained about the focus and the background for carrying out the study, as well as the objectives and methodological approach of the study. The contact person oriented the researcher at the research site for a period of four days. During the orientation period, the researcher was briefed about the ART clinics' objectives, strategies in place to achieve their objectives, and the activities.

A pilot study to test the IDI tool was done at Chiradzulu and Chikwawa district hospitals during the researcher's orientation period to the study sites.

During the main study, the informants were approached while waiting for their monthly consultations at the two study sites. The information about the research was given to the ART Clinic in two phases. First, as part of the general briefing (Health talk) that all clients received in an open area before the consultations begins and secondly, as a private conversation in a private room with the contact person. In order to maintain confidentiality, those who wished further information about the study or were interested to participate informed the contact person who was the last person every client met for booking date of next appointment. Informants who indicated willingness met the researcher who asked them a few questions to determine eligibility, and were given a date which was mutually agreed upon and the interviews took place either in morning or afternoon. Before the study the researcher informed participants about rights to withdraw from the study. For those who were ready for the interview, oral consent was obtained, recorded on the consent form by ticking and tape recorded. Oral consent was opted for because asking them to give a written consent would have been unethical in terms of confidentiality. To further protect confidentiality, a coding system was devised to refer to each informant, with the first letter referring to district where the study was conducted sex (CZ for Chiradzulu and CK for Chikwawa), the second to initial for home district and the third to sex, fourth to age, fifth to education, sixth to occupation and seventh to couple number. When the informants had consented to take part in the study, they were assured of confidentiality. The researcher informed the informants that they were free to quit if they so wished. During the research activity, all the informants were given refreshments in the form of snacks and transport reimbursements of about $\$ 2$.

IDIs were employed by the researcher in Chichewa. IDIs were opted for because they allow room to explore issues deeper, are interactive in nature, the interviewer can clarify issues during the process of interviewing, and offer possibilities of probing and modification of interview guides in the course of the study [32]. An interview guide was employed to ensure coherence in the study approach and to give the interview sessions a general direction with regards to topics raised and discussed. The guide comprised a section on demographic characteristics. It also had an outline of topics with open-ended questions covering the following aspects: child bearing issues. The guide was carefully translated from English to Chichewa. The quality of a translation was verified by an independent translator who translated it back into the original language. Original and back translated documents were then compared for consistency by the interviewer.
The couples were interviewed independently from their partners but on the same day to enable free expression of feelings and views. The IDIs were carried out at the area within the ART Clinic in offices or outside under trees where each informant felt comfortable and that their privacy would be maintained in order to promote confidentiality and a relatively relaxed atmosphere. The interviews lasted between 50 minutes to $2 \frac{1}{2}$ hours. All IDIs were transcribed verbatim.

\section{Data analysis}

General principles and procedures for qualitative data content analysis by Graneheim and Lundman, [33] were followed. The interviews were read through several times to obtain a sense of the whole. Then the texts about marriage were extracted which constituted the units of analysis. The texts were then divided into condensed meaning units which were later labelled with a code. Tentative categories of the codes were discussed between three researchers who initially did the coding independently. Once the codes were agreed upon, the underlying meaning of the different categories of the codes was formulated into themes. The four themes were; reasons/motivation for selection of the type of marriage partners, sources for the potential marriage partner, reaction of kin or extended family on the marriage partner selection and risk perception. All the data from digitally - recorded IDIs that was transcribed verbatim was typed. NVIVO version 9 was used to organize the data.

\section{Results}

\section{Characteristics of informants}

All the $20 \mathrm{CLWH}$ said that they were in a monogamous marriage relationship and their ages ranged from 23-49 years old with a mean age of 38 years. They were either living in their wives' or husbands' natal compounds depending on the marriage setting. Twenty-six informants (ten from the matrilineal and 16 from the patrilineal communities) had been living with HIV for less than five years. Ten from matrilineal and four from patrilineal communities had been living with HIV for more than five years. All couples reported being in a monogamous relationship. They were living in their wives' or their husbands' natal compounds depending on kinship organisation. Six informants had no formal education at all. Thirty-four informants had some schooling; 28 (14 from each community) had completed primary education while the other six had completed secondary school education (Form 4). Thirtythree of the informants were local farmers with small gardens and were without any other source of income. Only seven male informants had formal jobs. Poverty levels were widespread amongst all the informants. All of the informants were Christians.

Table 1 presents information on children and marriage status for the informants from matrilineal and patrilineal communities. The results show that regardless of the society organisation, the informants established several marriages (one-four) throughout their lifetime. Only ten of the informants are in their first marriage relationship. The reason for the new marriages is most often divorce. New marriages were established both among those who knew or did not know their HIV status at the time of marriage. However, ten couples, four from the matrilineal and six from the patrilineal communities, selected marriage partners that were living with HIV. All the four matrilineal couples who established their new marriages when they were HIV-positive had children with their newly married partners. While out of the six patrilineal couples who established their new marriages when they were HIV-positive, four had children (Table 1). 
Citation: Gombachika BC, Chirwa E, Sundby J, Malata A, Maluwa A, et al. (2012) Marriage Partner Selection by Heterosexual Couples Living with HIV from Rural Southern Malawi. J AIDS Clinic Res S1:016. doi:10.4172/2155-6113.S1-016

Page 4 of 8

\begin{tabular}{|c|c|c|}
\hline Characteristics & Matrilineal & Patrilineal \\
\hline $\begin{array}{l}\text { Number of informants in } \\
1^{\text {st }} \text { marriage } \\
2^{\text {nd }} \text { marriage } \\
3^{\text {rd }} \text { marriage } \\
4^{\text {th }} \text { marriage }\end{array}$ & $\begin{array}{l}1 \\
8 \\
0 \\
1\end{array}$ & $\begin{array}{l}5 \\
7 \\
0 \\
0\end{array}$ \\
\hline $\begin{array}{l}\text { Marital status before current marriage } \\
\text { Divorcée } \\
\text { Divorcé } \\
\text { Widow } \\
\text { Widower }\end{array}$ & $\begin{array}{l}7 \\
8 \\
2 \\
1\end{array}$ & $\begin{array}{l}4 \\
3 \\
2 \\
3\end{array}$ \\
\hline $\begin{array}{l}\text { Number of couples who had a positive } \\
\text { HIV status when getting married (current } \\
\text { marriage) }\end{array}$ & 4 & 6 \\
\hline $\begin{array}{l}\text { Place where informants who married } \\
\text { spouses living with HIV met their spouse } \\
\text { ART Clinic } \\
\text { PLWH gatherings }\end{array}$ & $\begin{array}{l}3 \\
1\end{array}$ & $\begin{array}{l}3 \\
3\end{array}$ \\
\hline $\begin{array}{l}\text { Number of couples who have children after } \\
\text { marrying spouses living with HIV }\end{array}$ & 4 & 4 \\
\hline
\end{tabular}

Table 1: Information on marriage and children.

\section{Marriage partner selection}

The purpose of the study was to explore marriage partner selection among CLWH in matrilineal and patrilineal communities. This paper focuses on couples that had re-married couples living with children following an HIV diagnosis in their current marriages. Three major themes were identified: the informants' reasons/motivation for selection of the type of marriage partner that they wanted, the source for the potential marriage partners and the reactions of kin or extended family on the marriage partner selection and perception of risk in their practice of marriage partner selection. In the following sections additional details regarding these perspectives are provided with illustrative quotations.

\section{Sources for potential marriage partners}

Most often the informants found their potential marriage partners at the ART clinic, support groups or other HIV-social networks emerged over time in the study. They indicated that although the main aim of PLWH groups is to promote positive living, some participate in order to find a marriage partner as indicated in the narrations.

"I met my second wife here at Ngabu hospital when I came for my appointment at the clinic (ART) and she also had come for the same. So knowing that I was tested (HIV) and she was also tested, I decided to propose marriage to her." Male from patrilineal community

"I met my second wife right here at the hospital when we had both come for our review. That was in 2000 as such we just thought it wise that it was a good decision for me to marry someone who also had a similar problem because we would understand each other easily and follow the advice that we are given here at the hospital without any problems." Male from patrilineal community

"I met my husband who was also in the support group (HIV/ AIDS). By then I had lost my husband. He told me that he was married but his wife who was HIV negative and her relatives were ill treating him." Female from matrilineal community

"I met him at one of our meetings as I told you that I am a member of a support group so it was during such meetings that we met. He was sent from Thyolo and I was also sent by Chiradzulu support group. During the meeting, we were assigned to work in groups and it is from the introductions that he discovered that I was single as he was so he proposed a marriage to me." Female from matrilineal community

Once they share their success stories about finding marriage partners living with HIV at the support group meetings, some PLWH looking for a marriage partner are compelled to attend the meetings as narrated below by a matrilineal woman who married a marriage partner living with HIV and ended up having a child who is HIV negative.

"Several people come to me asking; 'If you are HIV-positive where can you get a spouse who is also HIV positive? Some even ask; 'If you are HIV-positive and you want to get pregnant, what should you do?' I always tell them......"

However, the informants pointed out that the idea of finding marriage partners who are living with HIV never came from the health care workers: 'The doctors do tell us that [marry spouses living with HIV], it is our own decision.'

\section{Motivation for choosing a marriage partner}

Couples living with HIV indicated that they went for a marriage partner living with HIV because they felt that they would understand each other better (relate to their experiences) and that it was easy to follow the guidelines for positive living with HIV. Some of the informants indicated that during the period they were living with HIV, they needed a reliable marriage partner, one with whom they could support each other emotionally and help obtain important information in sustaining a positive life.

A male informant from a matrilineal community eloquently captured this theme by stating;

"I used to have general body pains and headaches every now and again. I would wake up well in the morning but later in the afternoon I would be very sick. I got tested in 2003, and was given the results which I accepted. I followed all the advice including the one about medications and joining support groups which I did right here at the hospital. When I informed my wife, she was astonished and in those days HIV issues were a big threat in the society. So she went straight to tell her relatives. From that day, she was very rude to me. I knew that my life was in danger which was contrary to the advice on positive living that I was given at the hospital. She used to say that: 'I cannot stay with a person who has a virus; it means you will also kill me.' However I used to tell her that she must also go for a test at the hospital in order to know how she was. She never followed my advice. Even her relatives were saying that; I must go back to my home village because they were uncomfortable to stay with me in their compound since I might infect them. I stayed on and followed the advice that I was given from the hospital. But the family was not showing love to me, I was discriminated and I felt that I was going to die faster. One day our relatives met for discussion and during the meeting she [the wife] said boldly that I was found with the virus as such she was ready for the divorce. I accepted. I brought my issue to the support group we discussed over it for so many days. They agreed with me that my life was at stake and suggested that I must find another wife who was also living with HIV because we would be able to understand each others health better. I started to look for one. Then I met my current wife here at the ART clinic. We started our relationship and explained to her about my previous marriage relationship and why I went for her because I wanted someone who would understand my situation."

Other informants echoed similar thoughts:

"But I needed someone to be taking care of me apart from that it will 
Citation: Gombachika BC, Chirwa E, Sundby J, Malata A, Maluwa A, et al. (2012) Marriage Partner Selection by Heterosexual Couples Living with HIV from Rural Southern Malawi. J AIDS Clinic Res S1:016. doi:10.4172/2155-6113.S1-016

Page 5 of 8

be easy for us to follow the counselling advice that they give us and we can live longer."Male from patrilineal community

'I met my second wife right here at the hospital when we had both come to for our review. That was in 2000 as such we just thought it wise that it was a good decision for me to marry someone who also had a similar problem because we would understand each other easily and follow the advice that we are given here at the hospital without any problems.' Male from patrilineal community

'That is why it is not good for a person who is on medications to get married with someone who is not on medications because it is difficult to follow the advice that we get from here. As a woman even if you tell your husband that this is what we are supposed to do, he just says; 'Why are you bringing your hospital stuff [condom use] in this marriage?' 'If you knew that you were positive (HIV), why did you decide to get married in the first place?' That is where the problem comes in. As such I just decided to get married to someone who is also like me because if I will be sick, he will know what to do, he is the one who will be able to take care of me, take me to the hospital.' Female from patrilineal community

Some indicated that living with HIV continues to pose stigma and discrimination as a result they were afraid of rejection by HIV negative people.This group's views can be summed up by a male informant who said

"If you want to get married rather marry someone who is also HIVpositive. It is because it is difficult for an HIV-positive person like me to be accepted by an HIV-negative person, it is even difficult to disclose your status. For example my wife, she used to have prospective suitors but some of the suitors' neighbours would discourage them that; 'The woman you want to marry has HIV'. As such one ends up resorting to finding a spouse who is also HIV-positive." Male from matrilineal community

Some deliberately selected marriage partners living with HIV to avoid transmitting the virus to HIV-negative person.

"He said that he was HIV-positive as such it was not fair for him to go for a woman that he does not know her status, thus he would rather take an HIV-positive woman." Female from matrilineal community

\section{Reactions of kin or extended family on the marriage partner selection}

In their separate interviews, some of their narratives revealed the ease in selecting a marriage partner. They all indicated that choice of marriage partner has changed from what it used to be several decades ago. Parents and extended relatives no longer helped in the identification and selection of a marriage partner for their children and that present day marriage is mainly a result of individual choices.

"The problem is that they just leave us on our own and they say, 'Just leave them, they will know what to do themselves this is not their first marriage." Male from matrilineal community

"My relatives would always ask me why I was not keen about getting married because all my peers were married. Sometimes they would arrange for boys to approach me. But I was very serious in choosing a husband in fact my first husband was the $15^{\text {th }}$ man to ask for a hand in marriage. I studied him for some time trying to figure out if he was really serious and if we would get along easily. I did not want to have a drunkard." Female from patrilineal community

Some informants indicated that even though marriage partner selection no longer involved their relatives' hand, there were reactions from their relatives once they took the issues of HIV-positive marriage partner selection in their own hands.

"I fell in love with her and I told her but when she showed her parents the luphato- (A gift in form of a wrapper and money given to a girl/ woman from her boyfriend as a sign of marriage proposal which she has to show to her parents) they told her that I am not a man enough and that I was not going to help her. I decided that she comes silently to my home village which she did and she stayed for 2 days. Her parents looked for her all over not knowing that she was in the same village. One day late in the afternoon her father discovered her in our compound and he beat her very much. I stood back because I could not fight with him being my father in-law moreover the child he was beating was his so I just stood by. Then after some time he started pulling her back to his house. But she ran away from her compound back to my house, the same day. The next day we run away from our parents to Fatima where we stayed for 7 months." Male from patrilineal community

"All along my father and my other relatives never used to get along with my boyfriend's home village which was sharing borders with our village. He never wished any of his daughters to get married from there because the youths were very mischievous and irresponsible, drinking beer, smoking and promiscuous. My boyfriend never gave up despite my relatives' resistance until finally he became part of the family." Female from matrilineal community

Some of the informants narrated that their parents wanted them to remain single than for them to have a marriage partner who was living with HIV, which they feared could lead to more illness and death.

"My parents told me that they were happy to see me well. They desired that I must not re-marry; not even a spouse that was living with HIV as I was. They were wondering how on earth a sickly couple would manage in a marriage relationship." Male from a matrilineal community

However, despite these disapprovals, the informants finally married and with time their parents accepted the choice of their marriage partners.

\section{Perceived behavioural risks}

The risks that the informants indicated stemming from positive partner selection were increase in ones viral load during unprotected sexual relationships and mother to child transmission (MTCT) of HIV. They heard the information about the indicated risks from support groups, radio, and during health talks at the hospital. Some of the information was thus either inaccurate or inadequate.

The informants indicated that they knew that they must use condoms to prevent re-infecting each other but the most salient issue in these informants was the conflict between risks of their behaviour and the need to satisfy the society norms. On one hand they want the intimacy and bonding by remarrying spouses living with HIV and having children, on the other hand they fear the consequences of pregnancy and increase in viral load.

"I know the dangers of HIV, childbearing, even unprotected relationships [sexual] but in my day to day life I do not think about it otherwise I will die faster. I cannot say no to re-marrying now because I have HIV, no, I need a companion. I am well and life has to go on because I do not know when God will call me. What is needed is to follow the instructions to prevent further acquisition of the virus." Male from a matrilineal community 


\section{Discussion}

Evidence emerging from this study indicates that PLWH are getting married and are having children. This newly emerging process is characterized by self selection of marriage partners who are living with HIV independent from parents and kin. The lack of society differences in the informant's narratives suggests that despite the structural differences in kinship organisation, CLWH are using the same strategies in marriage partner selection. The sources of the marriage partners are either at the ART Clinic or PLWH meetings. This practice, which has been documented elsewhere among people who are HIV-positive as well as those who are positive and receiving ART [34]; emerged over time in the study. This was suggested to them by peers living with HIV and not by counsellors or medical staff. Our informants' preference for same HIV-positive status in a marriage partner does not contradict the general argument of 'fear of marriage' $[14,15,16]$, however it provides an additional aspect to the interconnections of marriage and HIV in Malawi as HIV-positive appear less influenced by these notions of fear than expected. We argue that PLWH seek marriage partners living with HIV because HIV infection; evokes strong negative feelings in the communities and fuels discrimination and stigma and raise profound moral issues about individual rights and social interests in reproductive decisions, getting married and having children. Arguing along similar lines, Rhine, [15] indicates that for many people on ARVs the dilemma of how to find a marriage partner while living with HIV is addressed by seeking marriage partners that are also living with HIV. Hence support groups for PLWH, have become arenas for sexual networking and marriage markets and function to counter the social stigma surrounding reproductive decisions, HIV and AIDS. Informants narrated that their selection strategies were mainly motivated by their desire to find someone who would support them to live positively. They never expected people who are HIV-negative to accept their hand in marriage therefore this choice of a partner was also for fear of rejection. This confirms previous studies in Malawi, Uganda and USA that suitors perceived to be at high risk of having HIV are increasingly rejected as marriage partners by people who are HIV negative [35-37]. Confirming this behaviour, Suitor and Pillmer, [38], indicate that a person is more likely to choose an individual who is in similar situation or has sound knowledge in the issue. Moreover, socially similar people are more likely to have comparable life experiences, increasing the odds that they will understand one another's social circumstances and hold similar values. Rogers [39], describes it as homophilous, which is an obvious principle of human communication that the transfer of ideas occurs most frequently between individuals that are similar. Homophily may produce these patterns because individuals who share social statuses tend to hold similar values and are more knowledgeable about one another's circumstances, resulting in greater empathy [38].

Our findings expand prior work in rural Malawi by Watkins [37] and Clark et al. [40] which demonstrates a shift away from traditional practices on marriage partner selection practices towards individual preference in the era of HIV and AIDS. The HIV-positive status is reported to have a great influence on choice of a marriage partner for marriage. The shift is also consistent with the notion of individualization by Shanahan [41], where men and women exercise their independence in their life trajectories as traditional constraints are relaxed. As a consequence, adolescents and young adults have become increasingly responsible for finding their own marital partners.

The findings also show that the informants were counselled to use condoms consistently with their marriage partners who were also living with HIV to avoid re-infection. Their narrations indicate that they seemed to understand messages on re-infection but some never followed the advice evidenced from the children they had from these established marriage relationships. We note that despite the comprehensive counselling, some CLWH might examine their values and still decide that even a minimal risk of transmission to a partner or a child is unacceptable thus adhere to the positive prevention strategies. However, others may decide to take the risk due to social cultural pressures. What matters most is that people make a conscious decision based on the available information. To those who never had children it is difficult to ascertain use of condoms because sexual behaviour typically does not occur in public, making it difficult to verify reports of what people say they have or have not done.

Despite CLWH being aware of the risk of viral overload and MTCT of HIV, unprotected sex remains a critical issue because these CLWH ended up having children. Thus, awareness of these two risks did not translate into actual protection in their sexual behaviour. Research in some African settings suggests that although some risk behaviours actually decrease with ART, a substantial proportion continue to have unsafe sex [13,42-44].

Reniers and Helleringer [45], argue that by taking two HIV-infected individuals "off market", this relationship will reduce the likelihood that a susceptible person forms a serodiscordant partnerships and will thus lead to decline in HIV incidences. They further postulate that, similarly, if a man who tests negative purposefully seeks and finds a seroconcordant partner, then there will be fewer susceptible available for mixing with HIV infected individuals. However, clinical evidence confirms that people already infected with HIV can be re-infected with a different genetically variant of the virus. Exposure to a new strain of HIV risks genetic recombination that results in a potentially more difficult to treat virus commonly referred to as super-infection [46,47]. Kalichman et al. [48] indicate that HIV seroconcordant sex partners risk exposing themselves to other sexually transmitted pathogens that can potentially complicate the course of their HIV infection.

\section{Recommendations}

The study shows that PLWH established their new marriages when they were HIV-positive. They indicated that they chose a marriage partner living with HIV because they felt that they would understand each other well and that it was easy to follow the guidelines for HIV positive living. We are aware that if ignored it raises biomedical concerns on the risk of HIV super infection, viral recombination and transmission of drug resistant virus in cases where unprotected sex is practiced. Not downplaying the importance of the situations that these couples are in, however, we argue, if no intervention is put in place, Malawi's maternal and infant mortality due to HIV and AIDS will continue to be high. Hence, the counselling package for PLWH must include detailed information on risks involved in remarrying marriage partners living with HIV and ways to minimize these risks. Investment in training health care workers and peer- group leaders on HIV superinfection and reproductive decisions, reproductive rights, ethics and reproductive choices for CLWH would also make the rolling of the intervention successful.

Malawi should adopt a peer-group skills approach. This involves gaining access to already existing social networks of PLWH through key individuals, training them as peer educators then involving them in disseminating the risk messages through their networks, and then assessing the effects. The intervention might be rolled out as a pilot project in one rural health facility. Among other things, the intervention could also concentrate on improving access to and 
Citation: Gombachika BC, Chirwa E, Sundby J, Malata A, Maluwa A, et al. (2012) Marriage Partner Selection by Heterosexual Couples Living with HIV from Rural Southern Malawi. J AIDS Clinic Res S1:016. doi:10.4172/2155-6113.S1-016

Page 7 of 8

availability of reproductive health services to CLWH and integrate it with HIV treatment, care and PMTCT programmes. From the peergroup skills approach, a data base of best practices can be established that can be shared widely. This database can also be a starting point for other programmes and organisations dealing with PLWH as they either initiate or modify their HIV and AIDS services. The intervention will be based on the Theory of Planned Behaviour (TPB) developed by Ajzen in 1985 [49]. A detailed discussion of this theory is outside the scope of this paper, however, according to this theory, individuals are more likely to change a given behaviour if they believe that such behaviour increases their risk for a certain condition. And if they believe that this condition will form a serious threat to their health and well being. They are also more likely to make behavioural adjustments if they believe that behaviour change will reduce susceptibility to the condition or its severity and that the perceived benefits of changing the behaviour outweigh the potential negative effects.

There is need for further studies in Malawi to better inform policy and evidence based prevention strategies for PLWH, since issues of same positive HIV status selection have not been widely explored.

\section{Methodological considerations}

The study acknowledges that the median age of 36 years reflects an older sample than the majority of PLWH in Malawi, 15-25 years, where the highest prevalence is observed [17]. These results may have an implication because the marriage practices for the old and young CLWH might be different. However, apart from age, the other demographic characteristics reflect a similar picture to the Malawi population in general as indicated in NSO [17].

\section{Conclusion}

HIV status is important in the decisions that the CLWH make in terms of who they have to marry. However, once the new marriage relationships where both partners are living with HIV are established, the HIV status is no longer important in the decisions that the CLWH make in terms of child bearing. Concurring with Elford [10], these changing patterns serve to remind about the complexity of human and sexual behaviour. The lack of society differences in the informant's narratives suggests that despite the structural differences in kinship organisation, CLWH are using the same strategies in marriage partner selection. Use of a range of educational peer-group skills building approaches has also been successful in behavior modification but it needs time, as the results are not instant and they occur usually and largely outside the health services. This paper, however, does not aim at encouraging or discouraging PLWH to marry. Rather it aims at contributing to the public discussion about the value of marriage and children bearing in relation to risk of HIV and offer recommendations. The fact that PLWH are making reproductive decisions based on same HIV-positive status calls for further research.

\section{References}

1. Heard I, Sitta R, Lert F; the VESPA Study Group (2007) Reproductive choice in men and women living with HIV: evidence from a large representative sample of outpatients attending French hospitals (ANRS-EN12-VESPA Study). AIDS 21: S77-S82.

2. Kreno T, Van der Walt JS, Siegfried N, Cohen K (2009) Therapeutic drug monitoring of antiretrovirals for people with HIV. Cochrane Database Syst Rev 8: 7268 .

3. Russell S, Seeley J (2010) The transition to living with HIV as a chronic condition in rural Uganda: Working to create order and control when on antiretroviral therapy. Soc Sci Med 70: 375-382.
4. Gallant JE (2000) Strategies for long-term success in the treatment of HIV infection. JAMA 283: 1329-1334.

5. Hoffman IF, Martinson FE, Powers KA, Chilongozi DA, Msiska ED, et al. (2008) The year-long effect of HIV-positive test results on pregnancy intentions, contraceptive use and pregnancy incidence among Malawian women. J Acquir Immune Defic Syndr 47: 477-483.

6. Taulo F, Berry M, Tsui A, Makanani B, Kafulafula G, et al. (2009) Fertility intentions of HIV-1 infected and uninfected women in Malawi: a longitudinal study. AIDS Behav 13: 20-27.

7. Cooper D, Harries J, Myer L, Orner P, Bracken H, et al. (2007) "Life is still going on": reproductive intentions among HIV-positive women and men in South Africa. Soc Sci Med 65: 274-283.

8. Matthews LT, Mukherjee JS (2009) Strategies for harm reduction among HIVaffected couples who want to conceive. AIDS Behav 13: 5-11.

9. Paiva A, Santos N, Franca-Junior I, Filipe E, Ayers JR, et al. (2007) Desire to have children: Gender and reproductive rights of men and women living with HIV: A challenge to health care in Brazil. AIDS Patient Care and STDs 21: 268-277.

10. Elford J (2006) Changing patterns of sexual behaviour in the era of highly active antiretroviral therapy. Curr Opin Infect Dis 19: 26-32.

11. Remien RH, Mellins CA (2007) Long-term psychosocial challenges for people living with HIV: let's not forget the individual in our global response to the pandemic. AIDS 5: S55-S63.

12. Peltzer K, Ramlagan S (2010) Safer Sexual behaviours after 1 year of antiretroviral treatment in KwaZulu-Natal, South Africa: a prospective cohort study. Sex Health 7: 135-141.

13. Sarna A, Chersich M, Okal J, Luchters SM, Mandaliya KN, et al. (2009) Changes in sexual risk taking with antiretroviral treatment: influence of context and gender norms in Mombasa, Kenya. Cult Health Sex 11: 783-797.

14. Mukiza-Gapere J, Ntozi JP (1995) Impact of AIDS on marriage patterns, customs and practices in Uganda. Health Transit Rev 5: 201-208.

15. Rhine KA (2009) Support groups, marriage and the management of ambiguity among HIV-Positive women in northern Nigeria. Anthropological Quarterly 82 369-400.

16. Oleke C, Blystad A, Rekdal OB (2005) "When the obvious brother is not there": Political and cultural contexts of the orphan challenge in Northern Uganda. Soc Sci Med 61: 2628-2638.

17. National Statistical Office (2010) Malawi demographic and health survey. Zomba, Malawi.

18. Chimbiri AM (2007) The condom is an 'intruder' in marriage: Evidence from rural Malawi. Soc Sci Med 64: 1102-1115.

19. Grieser M, Gittelsohn J, Shankar AV, Koppenhaver T, Legrand TK, et al. (2001) Reproductive decision making and the HIVIAIDS epidemic in Zimbabwe. Journal of Southern African Studies 27: 225-243.

20. Kishindo P (1994) Family planning and the Malawian male. J Soc Dev Afr 9: 61-69.

21. Peters PE (1997) Against the odds. Matriliny, land and gender in the shire highlands of Malawi. Critique of Anthropology 17: 189-210.

22. Chirwa CW, Chizimba S (2009) Multiple concurrent sexual partnerships in Malawi. A formative qualitative study. Paper prepared for Research to Prevention (R2P).

23. Reniers G (2008) Marital strategies for regulating exposure to HIV. Demography 45: 417-438.

24. Schatz E (2005) 'Take your mat and go!': Rural Malawian women's strategies in the HIVIAIDS era. Cult Health Sex 7: 479-492.

25. Eaton LA, Kalichman SC, O'Connell DA, Karchner WD (2009) A strategy for selecting sexual partners believed to pose little/mo risk for HIV: Serosorting and its implications for HIV transmission. AIDS Care 21: 1279-1288.

26. Marks G, Millett GA, Bingham T, Lauby J, Murrill CS, et al. (2010) Prevalence and protective value of serosorting and strategic positioning among Black and Latino men who have sex with men. Sex Transm Dis 37: 325-327. 
Citation: Gombachika BC, Chirwa E, Sundby J, Malata A, Maluwa A, et al. (2012) Marriage Partner Selection by Heterosexual Couples Living with HIV from Rural Southern Malawi. J AIDS Clinic Res S1:016. doi:10.4172/2155-6113.S1-016

Page 8 of 8

27. Snowden JM, Raymond HF, McFarland W (2011) Seroadaptive behaviours among men who have sex with men in San Francisco: the situation in 2008. Sex Transm Infect 87: 162-164.

28. Patton M Q (2002) Qualitative research and evaluation methods. (3rdedn) Thousand Oaks CA: Sage.

29. Kuzel A (1992) Sampling in qualitative inquiry. In: Doing qualitative research (ed), B Crabtree and W Miller 31-44.

30. Green J and Thorogood N (2006) Qualitative methods for health research. (2ndedn), Thousand Oaks, CA: Sage.

31. Emerson R, Fretz R, Shaw L (1995) Writing Ethnographic Fieldnotes. (1stedn), The University of Chicago Press Ltd, London.

32. Morse $J$ and Richards $L$ (2007) Readme first for a user's guide to qualitative methods. (2ndedn), London: Sage Publications.

33. Graneheim U, Lundman B (2004) Qualitative content analysis in nursing research: concepts, procedures and measures to achieve trustworthiness. Nurse Educ Today 24: 105-112.

34. Shapiro K, Ray S (2007) Sexual health for people living with HIV. Reprod Health Matters15: 67-92.

35. Seeley J, Russell S, Khana K, Ezati E, King R, et al. (2009) Sex after ART: Sexual partnership established by HIV-infected persons taking anti-retroviral therapy in Eastern Uganda. Cult Health Sex 11: 703-716.

36. Steward WT, Remien RH, Higgins JA, Dubrow R, Pinkerton SD, et al. (2009) Behavior change following diagnosis with acute/early HIV infection-A move to serosorting with other HIV-infected individuals. The NIMH multisite acute HIV infection study: III. AIDS Behav 13: 1054-1060.

37. Watkins S (2004) Navigating AIDS in rural Malawi. Population and Development Review 30: 673-705.

38. Suitor JJ, Pillmer K (2002) Gender, social support and experiential similarity during chronic stress: the case of family caregivers. In Judith A. Levy and Bernice A. Pescosolido (eds), Social Networks and Health (Advances in Medical Sociology, 8), Emerald Group Publishing Limited, 247-266.
39. Rogers E (2003) Diffusion of Innovations (5thedn) 305 Free Press, New York.

40. Clark S, Poulin M, Kohler HP (2009) Marital aspirations, sexual behaviours, and HIVIAIDS in rural Malawi. J Marriage Fam 71: 396-416.

41. Shanahan MJ (2000) Pathways to adulthood in changing societies: Variability and mechanisms in life course perspective. Annual Review of Sociology 26: 667-692.

42. Coates TJ, Richter L, Caceres C (2008) Behavioural strategies to reduce HIV transmission: how to make them work better. Lancet 372: 669-684.

43. Bunnell R, Ekwaru JP, Solberg P, Wamai N, Bikaako-Kajura W, et al. (2006) Changes in sexual behaviour and risk of HIV transmission after antiretroviral therapy and prevention interventions in rural Uganda. AIDS 20: 85-92.

44. Luchters S, Chersich MF, Rinyiru A, Barasa MS, King'ola N, et al. (2008) Impact of five years of peer-mediated interventions on sexual behaviour and sexually transmitted infections among female sex workers in Mombasa, Kenya. BMC Public Health 8:143.

45. Reniers G, Helleringer S (2011) Serosorting and the evaluation of HIV testing and counseling for HIV prevention in generalized epidemics. AIDS Behav 15: $1-8$

46. Campbell MS, Gottlieb GS, Hawes SE, Nickle DC, Wong KG, et al. (2009) HIV1 superinfection in the antiretroviral therapy era: Are seroconcordant sexual partners at risk? PLoS One 4: e5690.

47. Poudel KC, Poudel-Tandukar K, Yasuoka J, Jimba M (2007) HIV superinfection: another reason to avoid serosorting practice. Lancet 370: 23.

48. Kalichman SC, Eaton L, Cherry C, Kalichman MO, Pope H, et al. (2010) HIV super-infection beliefs and sexual practices of people living with HIVIAIDS. Sexual Health 7: 420-424.

49. Ajzen I (2011) Behavioral Interventions: Design and evaluation guided by theory of planned behaviour. In: Mark MM, Donaldson SI, Campbell BC Social psychology program and policy evaluation. New York: Guildford 74-100. 